HoRTSCIENCE 26(7):896-898. 1991.

\title{
Fruit Set and Enlargement in Fertilized and Unfertilized Olive Ovaries
}

\author{
Hava F. Rapoport and Luis Rallo \\ Departamento de Agronomía, Universidad de Córdoba, Apartado 3048, \\ Córdoba 14080, Spain \\ Additional index words. abscission, Olea europaea, emasculation
}

\begin{abstract}
Fruit set and enlargement were compared for fertilized and unfertilized olive (Olea europaea L.) ovaries, the latter obtained by flower emasculation and bagging to prevent pollination. In the control population, the timing of abscission coincided with the onset of ovary expansion following fertilization. In the emasculated population, ovary expansion was only slight, and abscission was substantially delayed. Separation of the ovaries by size using graduated screens provided a useful tool for the evaluation of ovary growth.
\end{abstract}

In the olive there is a concentrated postanthesis period in which abscission of fertilized and unfertilized ovaries overlap (Rallo and Fernández-Escobar, 1985; Rallo et al., 1981; Rapoport and Rallo, 1991). To determine the factors causing olive flower and fruit abscission and to evaluate initial fruit set in pollination experiments, it is essential to distinguish between fertilized and unfertilized ovaries. This has been difficult because of the massive numbers of ovaries involved (Lavee, 1986; Rallo and Fernández-Escobar, 1985), the variability among

Received for publication 13 Apr. 1990. This research was supported by CAICYT PA 86/0092, Ministry of Education and Science, Madrid, Spain. We thank G.C. Martin for helpful suggestions concerning the manuscript. The cost of publishing this paper was defrayed in part by the payment of page charges. Under postal regulations, this paper therefore must be hereby marked advertisement solely to indicate this fact. flowers in the timing of anthesis and subsequent development events, and the necessity of observing all four ovules in anatomical studies (Rapoport and Rallo, 1991). In the present study, the persistence and growth of unfertilized ovaries was contrasted with that of the general (open-pollinated) population (mixed fertilized and unfertilized). Also, sizing ovaries by the use of a graduated series of screens was evaluated as a method to differentiate between fertilized and unfertilized ovaries by size.

Fertilization was prevented by emasculating and bagging olive flowers. 'Hojiblanca', a standard olive cultivar in southern Spain, was chosen for its ease of emasculation. In this cultivar, the stamens are firmly attached to the petals above their point of insertion, and the stigma is relatively short. Thus, the petals and stamens are easily removed together just before anthesis and with minimal contact with the stigma. Five trees were selected at the Alameda del Obispo experimental farm in Córdoba, Spain. Fifteen 


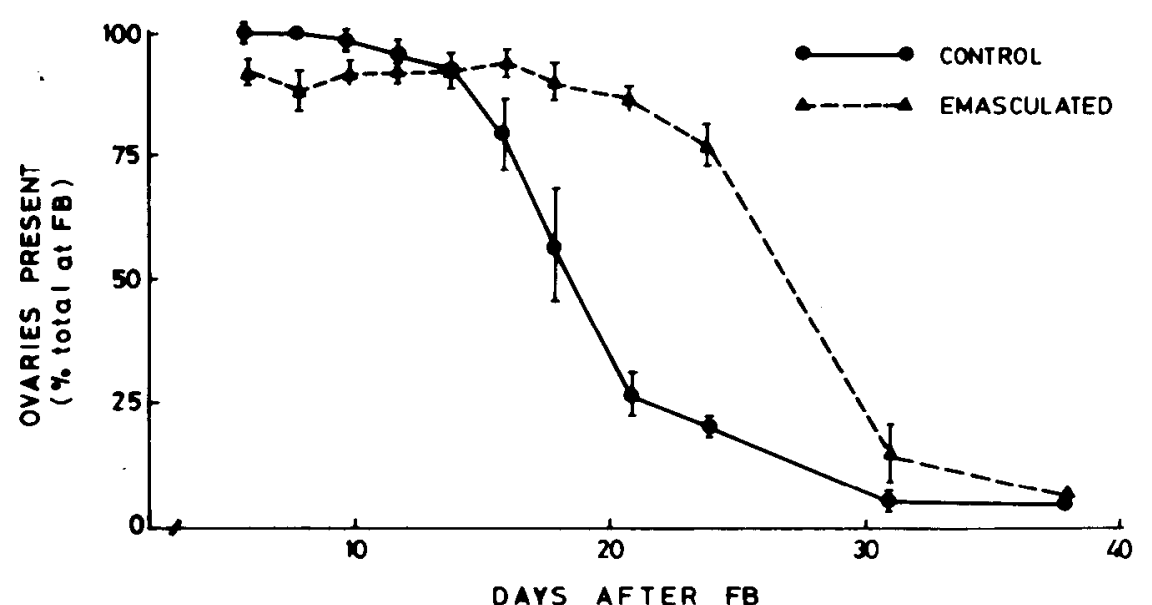

Fig. 1. Abscission pattern of olive ovaries from control and emasculated treatments following full bloom (FB). Bars represent \pm SE.

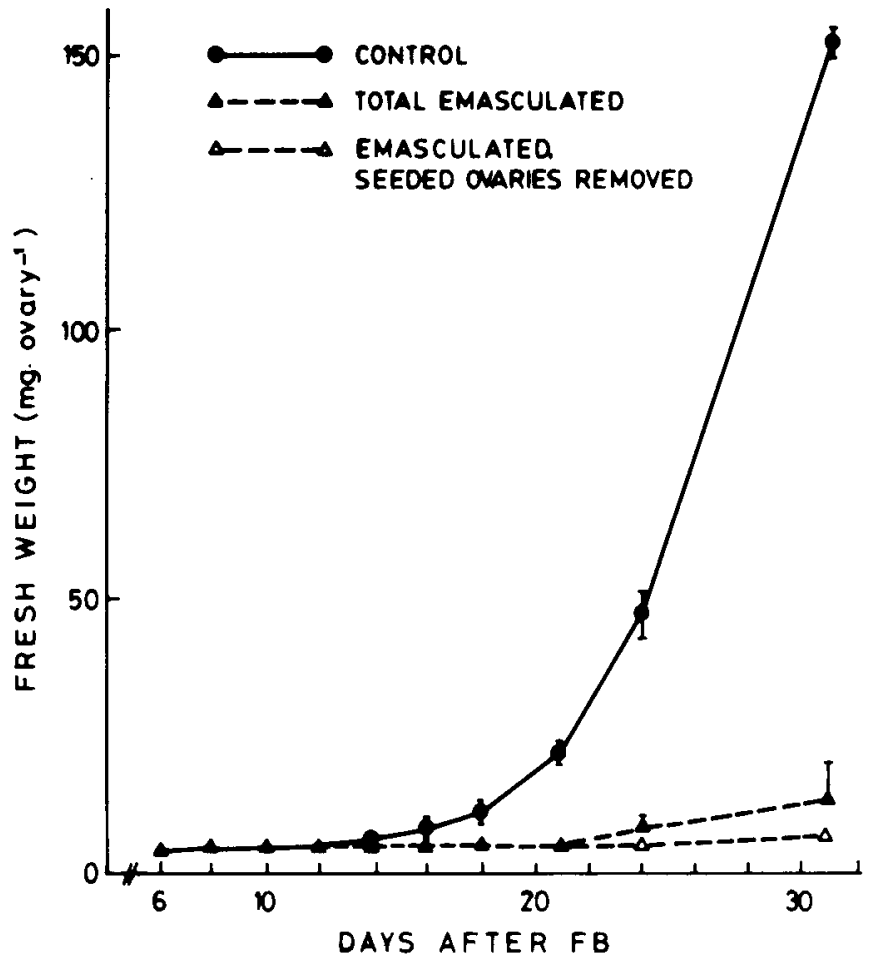

Fig.2. Fresh weight $( \pm$ SE) of olive ovaries from control and emasculated treatments following full bloom (FB). The data for the emasculated group were calculated both for all ovaries (total emasculated) and excluding the few large, seeded, and thus presumably fertilized ovaries [emasculated. seeded ovaries removed) (see text).

uniform, unbranched, flowering shoots per tree were emasculated as described above and 15 similar shoots per tree served as controls.

Full bloom (FB) was determined as the day on which more than $50 \%$ of the flowers were open on at least $70 \%$ of the inflorescences per shoot on $50 \%$ or more of the control shoots. Emasculation was done 3 to 5 days before FB. All imperfect and damaged flowers were removed, the remaining pistils were counted, and the treated shoots were covered with white muslin bags that were kept in place until pollen was no longer present in the orchard. On the control shoots, the initial number of perfect flowers was recorded as they opened from $\mathrm{FB}$ to $\mathrm{FB}+7$ days.

Five shoots (one per tree) per treatment were sampled at random from the previously prepared group every 2 days from 6 to 18 days after FB and at 21, 24,31, and 38 days after FB. All ovaries were counted, weighed, and vibrated through a graduated series of screens of 4.0-, 3.2-, 2.8-, 2.4-, 2.0-, and 1.6-mm mesh. Abscission data were obtained from the sampled shoots, with calculations based on the initial number of ovaries per shoot. These values ranged from 108 to 384 (perfect flowers) for controls and 94 to 314 (pistils) for the emasculated treatment.

Abscission of control flowers began at 10 to 12 days after $\mathrm{FB}$, was heavy from 14 to 20 days after FB, and then continued more gradually until the number of ovaries stabilized at 31 days after FB (Fig. 1). The same general pattern has been shown previously in this and other olive cultivars (Rallo and Fernández-Escobar, 1985; Rallo et al., 1981; Rapoport and Rallo, 1991). In the emasculated branches, there was an initial loss of $\approx 10 \%$ of the ovaries, most likely due to damage during treatment. Abscission of the remaining ovaries was delayed, relative to the untreated flowers, starting at 21 days after FB, although it followed a similar curve (Fig. $1)$.

On the control shoots, mean ovary fresh weight began to increase at 14 days after FB and increased dramatically after 18 days (Fig. 2 ). In the emasculated treatment, ovary fresh weight increased only slightly. The freshweight increase in that group was largely due to a few ovaries that, upon examination, were found to contain seeds, suggesting that those ovaries were fertilized in spite of the precautions taken. Thus, the ovary weights in Fig. 2 for the emasculated treatment were calculated both for all ovaries and with the large-seeded ovaries removed.

The distribution of ovaries by size in the control population was consistent from 6 to 12 days after FB, with the bulk of those ovaries accumulating in the 2-mm screen (Fig. 3 ). Although some ovaries were smaller (1.6$\mathrm{mm}$ screen), the 2-mm screen seems to represent ovary size before fruit growth for this cultivar. From 14 days after FB, the distribution of ovaries shifted to larger screens as time progressed, that is, once fertilization occurred and expansion commenced, the growing ovaries were collected in screens of progressively increasing sizes. The control ovaries found in the 2.4-mm screen as early as FB +6 could have been ovaries with large initial (unfertilized) size and/or older, already expanding fruits due to the asynchronous flower population.

The initial distribution of ovaries from the emasculated flowers, with the overwhelming majority collected in the 2-mm screen, was similar to that of the control group and changed only slightly during the progress of the study (Fig. 3). This pattern provides further evidence that the 2-mm screen represents ovary size before fruit growth. As the ovary count in the emasculated treatment changed little before 21 days after FB (Fig. 1 ), a slight increase in ovary size in this group is indicated by their presence in the $1.6-\mathrm{mm}$ screen early and in the 2.4-mm screen at later dates (Fig. 3). At 24 and 31 days after FB, few ovaries from the emasculated treatment were found in the 3.2- and $4.0-\mathrm{mm}$ screens (Fig. 3). These ovaries, discussed above, seem to have been fertilized (Fig. 2).

Badr and Crane (1965) found varying degrees of expansion in unpollinated almond, peach, apricot, cherry, and pear ovaries. In all cases, however, growth was much less than in fertilized (open-pollinated) treatments and ceased within 10 to 27 days after bloom. These results are consistent with our observations for olive (Figs. 2 and 3). Badr and Crane (1965) also reported that unpollinated ovaries from emasculated apricot and almond flowers were consistently smaller than unpollinated ovaries from intact flowers. 
CONTROL BRANCHES

EO EMASCULATEO

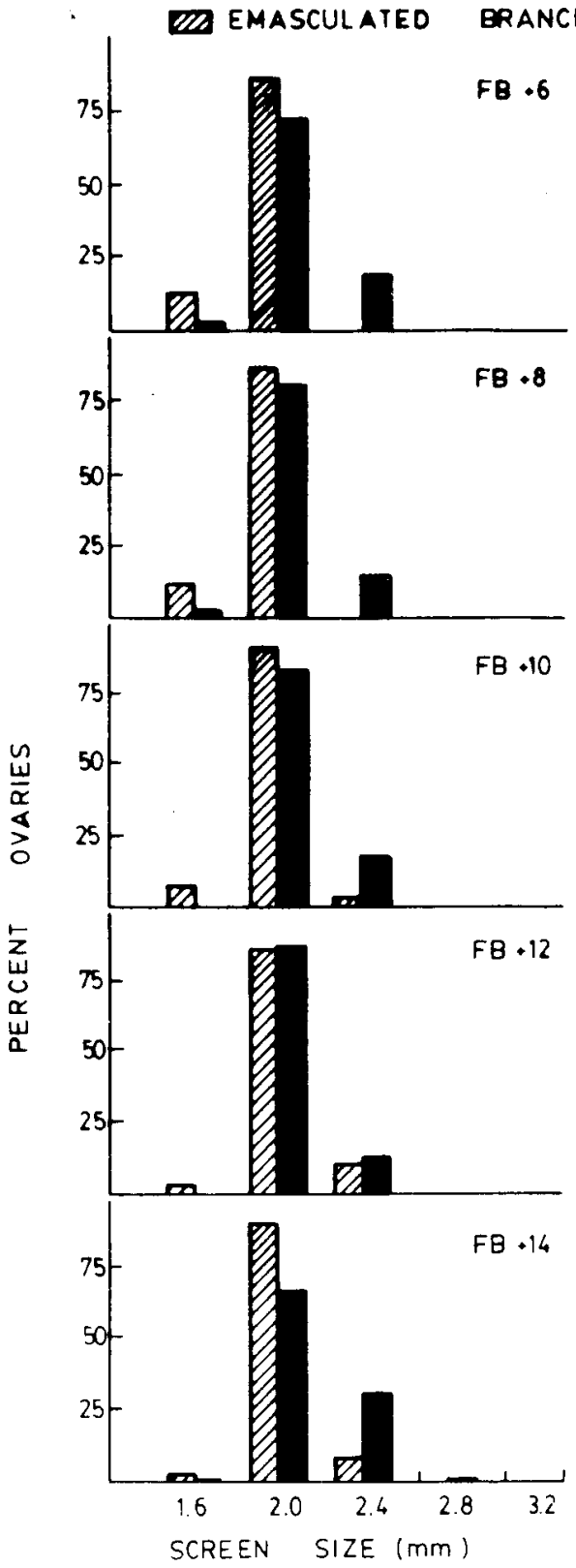

$\mathbf{F B} \cdot \mathbf{1 6}$
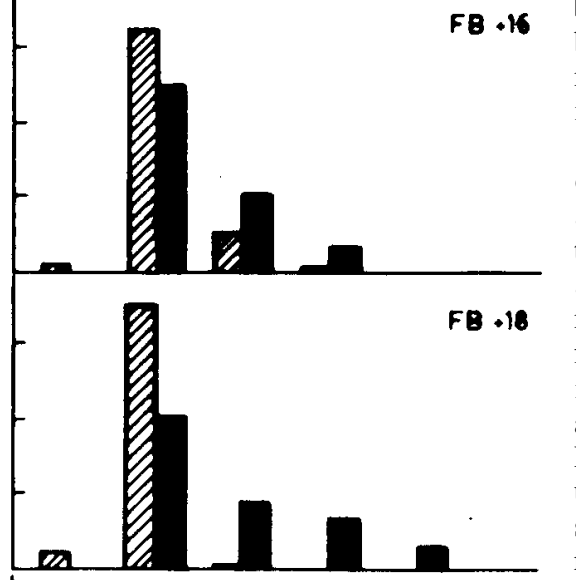

$\mathrm{FB}+21$

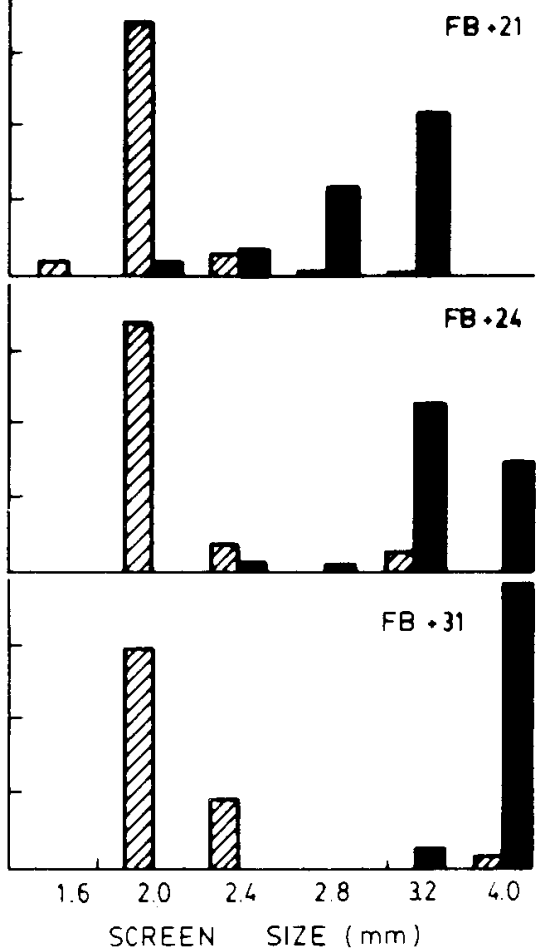

Fig. 3. Percent distribution of olive ovaries from control and emasculated treatments among graduated screens at varying times (number of days) after full bloom (FB). As all persistent ovaries were included, total number of ovaries is represented in Fig. 1.

Smaller olive ovary size due to flower emasculation is suggested by larger percentages

in the 1.6-mm class and less in the 2.4-mm class in this group than in the controls at 6

to 10 days after FB (Fig. 3). Reduced ovary growth following emasculation might be caused by a loss of nutrients usually supplied by the perianth (Brad and Crane, 1965) or by water stress due to damage during treatment or exposure of the pistil after perianth removal.

The dramatic increase in abscission in the control population between 14 and 16 days after FB (Fig. 1) coincided with the onset of the increase in ovary fresh weight (Fig. 2) and ovary size (Fig. 3). This coincidence may reflect the competitive triggering of perfect flower abscission by pollination, fertilization, and/or early fruit expansion (Rallo and Fernández-Escobar, 1985; Rapoport and Rallo, 1991). In the emasculated flower population that trigger was eliminated and abscission was delayed (Fig. 1). A similar response occurs in parthenocarpic fruits of 'Swan Hill' and 'Manzanillo' olives in which delayed abscission is associated with the absence of normal fertilized fruit development (Rallo et al., 1981).

The screen separation method by ovary size is a useful rapid tool to help distinguish fertilized from unfertilized ovaries and to indicate ovary growth trends within an asynchronous population, as in olive. For 'Hojiblanca', ovaries in the 2.8-mm-size class or larger and most ovaries in the 2.4-mm class appear to be fertilized. The 2-mm class (and to a small extent the 2.4-mm class) includes both unfertilized and recently fertilized ovaries in which expansion has not yet begun.

\section{Literature Cited}

Badr, S. and J.C. Crane. 1965. Growth of unpollinated ovaries of several deciduous fruit species. Proc. Amer. Soc. Hort. Sci. 87:163167.

Lavee, S. 1986. Olive, p. 267-276. In: S.P. Monselise (ed.). Handbook of fruit set and development. CRC Press, Boca Raton, Fla.

Rallo, L. and R. Fernández-Escobar. 1985. Influence of cultivar and flower thinning within the inflorescence on competition among olive fruit. J. Amer. Soc. Hort. Sci. 110:303-308.

Rallo, L., G.C. Martin, and S. Lavee. 1981. Relationship between abnormal embryo sac development and fruitfulness in olive. J. Amer. Soc. Hort. Sci. 106:813-817.

Rapoport, H. and L. Rallo. 1991. Postanthesis flower and fruit abscission in 'Manzanillo' olive. J. Amer. Soc. Hort. Sci. 116:720-723. 